\title{
Efficacy and safety of ustekinumab in East Asian patients with moderately to severely active ulcerative colitis: a subpopulation analysis of global phase 3 induction and maintenance studies (UNIFI)
}

\author{
Tadakazu Hisamatsu ${ }^{1}$, Hyo Jong Kim² ${ }^{2}$, Satoshi Motoya ${ }^{3}$, Yasuo Suzuki ${ }^{4}$, Yoshifumi Ohnishi ${ }^{5}$, Noriyuki Fujii ${ }^{6}$, \\ Nobuko Matsushima ${ }^{6}$, Richuan Zheng ${ }^{6}$, Colleen W. Marano ${ }^{7}$ \\ ${ }^{I}$ Department of Gastroenterology and Hepatology, Kyorin University School of Medicine, Tokyo, Japan; ${ }^{2}$ Center for Crohn's and Colitis, \\ Department of Gastroenterology, Kyung Hee University College of Medicine, Seoul, Korea; ${ }^{3}$ IBD Center, Hokkaido Prefectural Welfare Federation \\ of Agricultural Cooperative, Sapporo-Kosei General Hospital, Hokkaido; ${ }^{4}$ Division of Gastroenterology and Hepatology, Department of Internal \\ Medicine, Toho University Sakura Medical Center, Sakura, ${ }^{5}$ Division of Gastroenterology, Shizuoka Medical Center, Shizuoka; ${ }^{6} J a n s s e n$ \\ Pharmaceutical K.K., Tokyo, Japan; ${ }^{7}$ Janssen Research \& Development, LLC, Spring House, PA, USA
}

Background/Aims: We aimed to evaluate the efficacy and safety of ustekinumab (UST) in the East-Asian population with moderate to severely active ulcerative colitis (UC). Methods: This sub-analysis was conducted on data from East-Asian patients included in the UNIFI program (NCT02407236). UNIFI consisted of two double-blind, placebo-controlled trials: an 8-week induction study and a 44-week randomized withdrawal maintenance study. Results: Of 133 East-Asian patients (Japanese: 107, Korean: 26) who underwent randomization, 131 completed induction study and 111 entered maintenance study. In the maintenance study, 78 patients were randomized. Patients who received UST $130 \mathrm{mg}$ and UST $6 \mathrm{mg} / \mathrm{kg}$ showed numerically higher clinical remission at week 8 in the induction study (5/44 [11.4\%] and 5/45 [11.1\%], respectively) compared with those who received placebo $(0 / 44,0 \%)$. The proportion of patients achieved clinical remission at week 44 was numerically higher in the UST $90 \mathrm{mg}$ q12w group $(10 / 21,47.6 \%)$, but similar in the UST $90 \mathrm{mg} \mathrm{q8w}$ group $(5 / 26,19.2 \%)$ compared to placebo $(7 / 31,22.6 \%)$. Serious adverse events were reported in 1 patient in UST $130 \mathrm{mg}$ group, but no patient in UST $6 \mathrm{mg} / \mathrm{kg}$ group through week 8 in the induction study, and 1 patient in UST $90 \mathrm{mg} \mathrm{q12w}$ group and 5 patients in the UST $90 \mathrm{mg} \mathrm{q} 8 \mathrm{w}$ group in the maintenance study. No deaths were reported in East-Asian patients throughout the study. Conclusions: UST induction and maintenance treatments were effective in East-Asian patients with moderate to severe UC; the efficacy and safety profiles were consistent with the overall population. (Intest Res 2021;19:386-397)

Key Words: East-Asian; Ulcerative colitis; Subgroup analysis; UNIFI; Ustekinumab

\section{INTRODUCTION}

Ulcerative colitis (UC) is a chronic inflammatory disorder of unknown etiology involving the surface mucosa, the crypt epi-

Received June 30, 2020. Revised September 29, 2020

Accepted October 3, 2020.

Correspondence to Noriyuki Fujii, Janssen Pharmaceutical K.K., 3-5-2

Nishi-kanda, Chiyoda-ku, Tokyo 101-0065, Japan. Tel: +81-3-4411-7700

Fax: +81-3-4411-5086,E-mail: NFujii5@its.jnj.com thelium, and submucosa of the colon. ${ }^{1}$ Until recently, the prevalence of UC was lower in Asia as compared to Western countries. $^{2}$ However, prevalence in Asia, especially in urbanized East Asian regions, has increased sharply over the past few decades, with the annual prevalence rate of UC per 100,000 estimated to be $172.9^{1,3-6}$ The diagnosis of UC is based on specific guidelines developed for each region and country in Asia, and these are consistent with those used in the United States and the European Union. ${ }^{7-10}$ The goal of UC treatment, in gen- 
eral, is the induction of disease remission followed by a sustained and durable period of steroid-free remission in order to improve quality of life, and prevent the morbidity including hospitalization, surgery and minimization of cancer risk. ${ }^{8,11}$ Treatments available in East Asian countries include conventional therapies (e.g., mesalamine, glucocorticoids, and thiopurines) as well as advanced therapies such as antibodies against tumor necrosis factor-alpha (TNF- $\alpha$; e.g., infliximab, adalimumab, ${ }^{12}$ and golimumab), the $\alpha 4 \beta 7$ integrin antagonist (vedolizumab $^{13}$ ), and the Janus kinase inhibitor (tofacitini ${ }^{14}$ ), which are generally similar to those available in Western countries. Regardless of these therapies, not all patients can successfully respond to induction therapy and $20 \%$ to $40 \%$ patients who initially respond to the approved therapies may lose response over time (secondary loss of response), with antidrug antibodies being the leading contributor to secondary loss of response for biologic therapies. ${ }^{8,15-22}$ In addition, currently approved therapies are associated with increased safety risks such as infec$\operatorname{tion}^{23-25}$ and malignancies. ${ }^{26}$ Therefore, there remains an unmet need for novel therapies with alternative mechanisms of action and an improved benefit-risk profile for the treatment of UC.

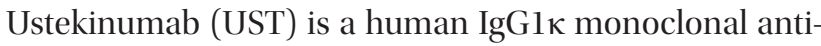
body that binds with high affinity and specificity to the p40 subunit common to both human interleukin (IL)-12 and human IL-23. UST is approved in several countries including Japan and Korea for patients with psoriasis and psoriatic arthritis as well as Crohn's disease who do not adequately respond to conventional treatments. UST demonstrated a consistent efficacy and safety profile in the Japanese Crohn's disease population compared to the overall population in the UNITI program. ${ }^{27,28}$ For UC, a phase 3 program (CNTO1275UCO3001 [UNIFI; NCT02407236]) demonstrated the efficacy and safety of UST in patients with active UC in the overall population studied in the program. ${ }^{29}$ Here, we report the efficacy and safety of UST in the East Asian subpopulation of the UNIFI studies.

\section{METHODS}

\section{Patients}

East-Asian patients who participated in the UNIFI program ${ }^{29}$ were included in this analysis. As reported previously, the UNIFI program included adult patients ( $\geq 18$ years of age) with moderate-to-severe UC (defined as a total Mayo score of 6-12) and a Mayo endoscopic subscore of 2 or 3, as determined during central review of video-endoscopy. ${ }^{30}$ Patients had an inad- equate response or intolerance to TNF- $\alpha$ antagonists, vedolizumab or conventional nonbiologic therapy (i.e., corticosteroids and/or 6 mercaptopurine/azathioprine) at the time of enrolment. Key exclusion criteria were imminent colectomy, gastrointestinal conditions that would result in surgery or confound disease-activity assessment, cancer, and active infections (including tuberculosis). Patients who had received previous treatment with IL-12 or IL-23 antagonists were excluded. Previous TNF- $\alpha$ antagonist, vedolizumab or other specified therapies were to be discontinued before study entry as specified in the protocol. ${ }^{29}$

\section{Study Design}

UNIFI program consisted of two double-blind, placebo-controlled trials; an 8-week induction study and a 44-week randomized withdrawal maintenance study (Supplementary Fig. 1) conducted under a single protocol. ${ }^{29}$ Briefly, patients were randomly assigned in a 1:1:1 ratio, stratified according to biologic failure status (yes or no) and region (Eastern Europe, Asia or rest of world), to receive intravenous (IV) UST $130 \mathrm{mg}$, a weight-range-based dose that approximated $6 \mathrm{mg}$ of UST per kilogram of body weight (UST $6 \mathrm{mg} / \mathrm{kg}$ ) or placebo in the induction study. Patients assigned to placebo who were not in clinical response (defined as a decrease in the total Mayo score of $\geq 30 \%$ and of $\geq 3$ points from baseline, with an accompanying decrease of $\geq 1$ point of the Mayo rectal bleeding subscore or a Mayo rectal bleeding subscore of 0 or 1 ) at week 8 , received induction therapy with UST $6 \mathrm{mg} / \mathrm{kg}$ and were followed for 8 weeks (up to study week 16). Patients assigned to UST who were not in clinical response at week 8 received $90 \mathrm{mg}$ of subcutaneous (SC) UST and followed for 8 weeks (up to study week 16). All treatments at week 8 were administered as both, an IV infusion and SC injection, to maintain the blind. Patients who did not respond to UST at week 16 did not enter maintenance study and discontinued. In the maintenance study, patients who were in clinical response with IV UST during induction study were randomized in a 1:1:1 ratio with stratification according to induction treatment (UST $130 \mathrm{mg}$, UST $6 \mathrm{mg} / \mathrm{kg}$, or placebo followed by UST $6 \mathrm{mg} / \mathrm{kg}$ ), status of clinical remission (defined as a Mayo score $\leq 2$ points, with no individual subscore $>1$ [yes or no]) at maintenance baseline, and oral corticosteroid use (yes or no) at maintenance baseline to receive maintenance therapy with SC UST $90 \mathrm{mg}$ every 12 weeks (q12w), UST 90 mg every 8 weeks (q8w), or placebo. Patients who achieved a clinical response to placebo during the induction study received SC placebo and those who had a delayed 
response to UST (at week 16) received SC UST $90 \mathrm{mg} \mathrm{q8w}$ during the maintenance study and were not randomized. Treatment with UST was administered through at least 1 year of combined induction and maintenance therapy; with a followup of additional 3 years for eligible patients in a long-term extension. The independent ethics committee or institutional review board at each study site approved study protocols. Written informed consent was obtained from all patients prior to enrolling into the study.

\section{Efficacy and Safety Evaluations}

The primary endpoint in the induction study was clinical remission at week 8 . The secondary endpoints at week 8 included endoscopic improvement (defined as a Mayo endoscopic subscore of 0 or 1 ), clinical response and change from induction baseline in the total score of the Inflammatory Bowel Disease Questionnaire (IBDQ). Other endpoints included changes in partial Mayo score (defined as the Mayo score without the endoscopic subscore), fecal calprotectin (F-CP), and C-reactive protein (CRP) through week 8, histologic improvement (defined as $<5 \%$ neutrophils in epithelium, no crypt destruction, and no erosions or ulcerations or granulations), histo-endoscopic mucosal healing (defined as a combination of both endoscopic and histologic improvement), symptomatic remission (defined as a Mayo stool frequency subscore of 0 or 1 and a Mayo rectal bleeding subscore of 0 ), and partial Mayo remission (defined as a partial Mayo score $\leq 2$ ) at week 8 . Clinical remission and clinical response at week 8 were evaluated by biologic failure status. In patients who did not have a clinical response to IV UST at week 8, clinical response, clinical remission, endoscopic improvement, and histo-endoscopic mucosal healing were assessed at week 16 . The analysis of all endpoints that include the Mayo endoscopic subscore was based on the score determined during central review of endoscopy.

The primary endpoint in the maintenance study was clinical remission at week 44 . Relative change from the maintenance baseline in clinical remission at week 44 were also calculated. The major secondary endpoints included maintenance of clinical response through week 44, endoscopic improvement at week 44 , corticosteroid-free clinical remission at week 44 (defined as being in clinical remission at week 44 and not receiving concomitant corticosteroids at week 44), and maintenance of clinical remission through week 44 among the patients who had achieved clinical remission at maintenance baseline. Other study endpoints included histo-endoscopic mucosal healing at week 44, changes in median IBDQ score, partial Mayo score, symptomatic remission, partial Mayo remission, F-CP, and CRP through week 44. For patients who had a clinical response to SC UST at week 16 during the induction study, clinical remission at week 44 and clinical response through week 44 were assessed. Clinical remission and clinical response at week 44 were evaluated by biologic failure status, which is either previous treatment failure with biologics or no history of treatment failure with biologics (either biologic naïve or had received biologics but did not have documented treatment failure).

Safety assessments included adverse events (AEs), serious AEs (defined as any AE at any dose that results in death, is life threatening, requires initial or prolonged hospitalization, results in persistent or significant disability/incapacity, may have caused a congenital anomaly/birth defect, or requires intervention to prevent permanent impairment or damage), infections and serious infections, and infusion/injection-site reactions during the follow-up period. Deaths, malignancies, opportunistic infections, tuberculosis, and cardiovascular events in the maintenance study were summarized.

\section{Pharmacokinetics and Immunogenicity}

Serum UST concentrations were evaluated at all visits during the induction study and every 4 weeks in the maintenance study. Antibodies to UST were evaluated by means of a drugtolerant electrochemiluminescence assay at weeks $0,4,8$, and 16 (in patients who did not have a response to induction therapy at week 8) during induction and at weeks 4, 12, 24, 36, and 44 during maintenance.

\section{Statistical Analysis}

Statistical methods used for the overall population has been described previously. ${ }^{29}$ All analyses for East-Asian patients were performed as post hoc. Descriptive statistics were reported for baseline characteristics. Unless otherwise specified, all efficacy analyses were based on the intention-to-treat principle. The statistical tests of efficacy results for East-Asian population were considered nominal and statistical values were not shown in this manuscript. Data sets for the main efficacy analyses comprise the patients who underwent randomization in the induction study or maintenance study. Prespecified efficacy analyses were also conducted for patients who entered the maintenance study after having a delayed response to UST.

Patients were considered not to have reached dichotomous endpoints if they had a prohibited change in concomitant medication for UCs, had undergone an ostomy, or colectomy be- 
fore week 8 (during induction) or week 44 (during maintenance), had used a rescue medication after a clinical flare (during maintenance), or had discontinued UST or placebo owing to lack of efficacy or an AE of worsening disease during maintenance, or had missing data. For continuous endpoints, patients who had a treatment failure had their value at baseline in the induction study carried forward from the time of the event onward. In addition, to explore the factors impacting the primary endpoint in the maintenance study, logistic analysis was conducted to provide the adjusted odds ratios and $95 \%$ confidence intervals (CIs) using the stratification variables for the maintenance study. In the safety analyses, data for patients who received at least one dose of UST or placebo in the induction study were analyzed according to the substance received, and data for patients who received at least one dose of UST or placebo in the maintenance study were analyzed according to the assigned study group. The frequency and types of AEs were summarized. Immunogenicity analyses included patients who had at least one blood sample obtained after UST administration.

\section{RESULTS}

\section{Patients}

Of the 133 East-Asian patients (107 Japanese and 26 Korean patients) who underwent randomization, 131 patients completed the induction study: 111 (83.5\%) entered the maintenance study and $20(15.0 \%)$ did not enter the maintenance study but completed the final safety visit (Fig. 1). In the maintenance study, 78 East-Asian patients were randomized and 33 (22 with delayed response to UST and 11 with response to placebo) were not. Most patients $(\mathrm{n}=74,95.0 \%)$ who underwent randomization and all non-randomized patients in the maintenance study completed the week 44 assessment.

Patients were randomly assigned to receive a single IV infusion of placebo $(\mathrm{n}=44)$, UST $130 \mathrm{mg}(\mathrm{n}=44)$ or UST $6 \mathrm{mg} / \mathrm{kg}$ $(\mathrm{n}=45)$ at baseline in the induction study, and patients who had a clinical response 8 weeks following IV UST induction were randomly assigned to receive SC injection of placebo $(\mathrm{n}=31)$, the UST $90 \mathrm{mg} \mathrm{q12w}(\mathrm{n}=21)$, or the UST $90 \mathrm{mg} \mathrm{q} 8 \mathrm{w}$ $(\mathrm{n}=26)$ in the maintenance study. At baseline of induction the majority were men $(87 / 133,65.4 \%)$ with a mean age 42 (standard deviation [SD]: 14.18) years and a mean duration of UC disease 7.85 (SD: 6.059). Disease characteristics at induction baseline were generally similar across study groups in both the induction and maintenance studies (Table 1), however, in the maintenance study, there were slight differences in CRP
(UST $90 \mathrm{mg}$ q12w group $1.7 \mathrm{mg} / \mathrm{L}$, UST $90 \mathrm{mg} \mathrm{q} 8 \mathrm{w}$ group 3.5 $\mathrm{mg} / \mathrm{L}$ and placebo group $1.4 \mathrm{mg} / \mathrm{L}$ ), F-CP ( UST $90 \mathrm{mg} \mathrm{q12w}$ group $1,202.0 \mathrm{mg} / \mathrm{kg}$, the UST $90 \mathrm{mg} \mathrm{q} 8 \mathrm{w}$ group $1,558.0 \mathrm{mg} /$ $\mathrm{kg}$, and placebo group $925.0 \mathrm{mg} / \mathrm{kg}$ ), and also in the proportion of patients in clinical remission at baseline of the maintenance study (the UST $90 \mathrm{mg} \mathrm{q12w}$ group 14.3\%, the UST 90 mg q8w group 11.5\%. and placebo group 25.8\%).

A total of 85 East-Asian patients who were randomized had previous treatment failure with biologic agents; all had treatment failure with at least one TNF- $\alpha$ antagonist; 4 out of 85 (4.7\%) with both a TNF- $\alpha$ antagonist and vedolizumab. Among the 48 patients who did not have previous treatment failure with biologics, 40 out of 48 (83.3\%) had not received biologics and 8 out of $48(16.7 \%)$ had received biologics but did not have documented treatment failure (Table 1).

\section{Induction Therapy}

A numerically greater proportion of East-Asian patients in the UST $130 \mathrm{mg}(5 / 44,11.4 \%)$ and $6 \mathrm{mg} / \mathrm{kg}$ groups $(5 / 45,11.1 \%)$ were in clinical remission at week 8 (primary endpoint) compared with the placebo group, in which none of the patients had remission (Fig. 2). Numerically greater proportions of patients in the UST $130 \mathrm{mg}(23 / 44,52.3 \%)$ and $6 \mathrm{mg} / \mathrm{kg}(27 / 45$, $60.0 \%$ groups achieved clinical response at week 8 than in the placebo group $(10 / 44,22.7 \%)$. The clinical remission and response rates in the East-Asian population were comparable with those observed in the overall population (Fig. 2).

Numerically greater proportions of East-Asian patients in the UST groups achieved endoscopic improvement (20.5\% in UST $130 \mathrm{mg}$ and $17.8 \%$ in $6 \mathrm{mg} / \mathrm{kg}$ ) and histo-endoscopic mucosal healing (18.2\% in UST $130 \mathrm{mg}$ and $11.1 \%$ in $6 \mathrm{mg} / \mathrm{kg}$ ) at week 8 compared with none in the placebo group (Fig. 2). Among East-Asian patients, 13/43 (30.2\%) patients in UST $130 \mathrm{mg}$ and $16 / 44$ (36.4\%) patients in the $6 \mathrm{mg} / \mathrm{kg}$ groups had histologic improvement compared with 5/43 (11.6\%) patients in the placebo group. Patients who received UST induction therapy were more likely to experience symptomatic remission than those who received placebo (43.2\% in UST $130 \mathrm{mg}$ and $44.4 \%$ in UST $6 \mathrm{mg} / \mathrm{kg}$ vs. 29.5\% in placebo group). Median change from baseline in IBDQ was numerically greater in UST-treated patients than in the placebo group (Supplementary Table 1). Through week 8, the change from baseline in partial Mayo score, F-CP and CRP in East-Asian patients were consistent with those observed in the overall population (Supplementary Fig. 2). More patients who were naïve to biologic therapy or nonbiologic failure had clinical remission and clinical response at week 8 
A Induction study

\section{(1)}

Week 0
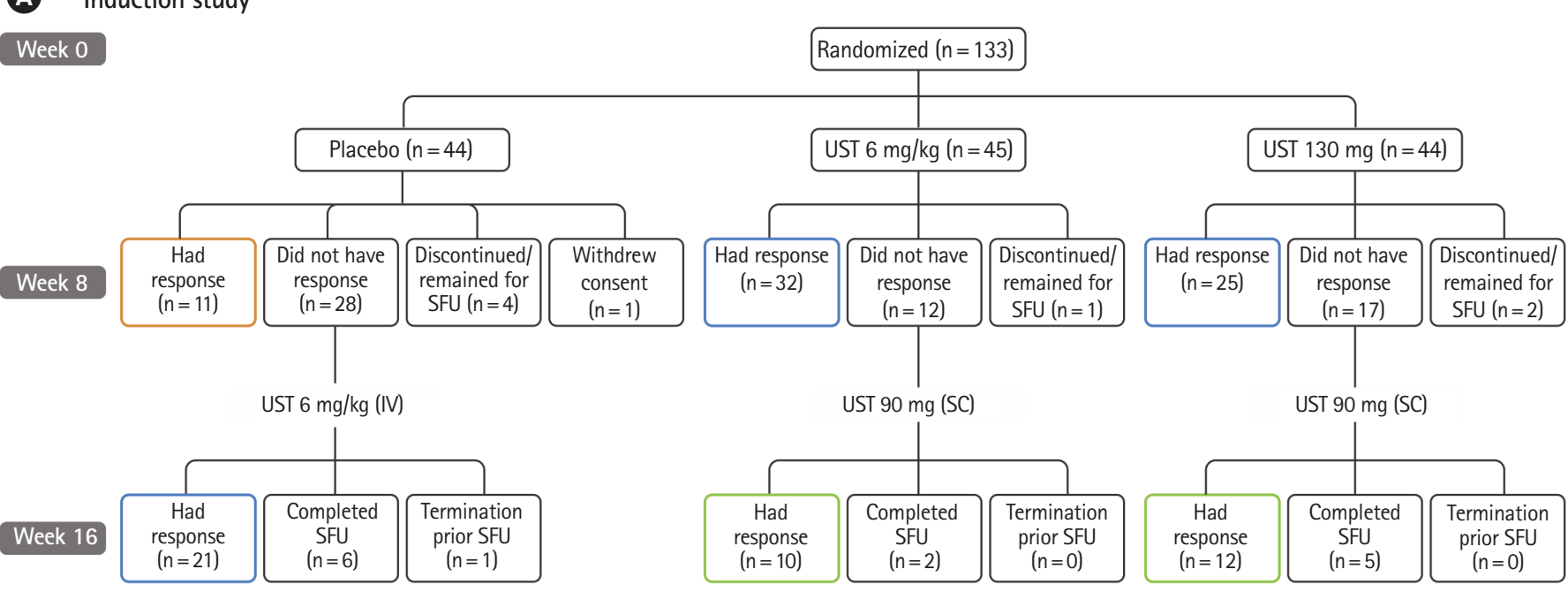

B
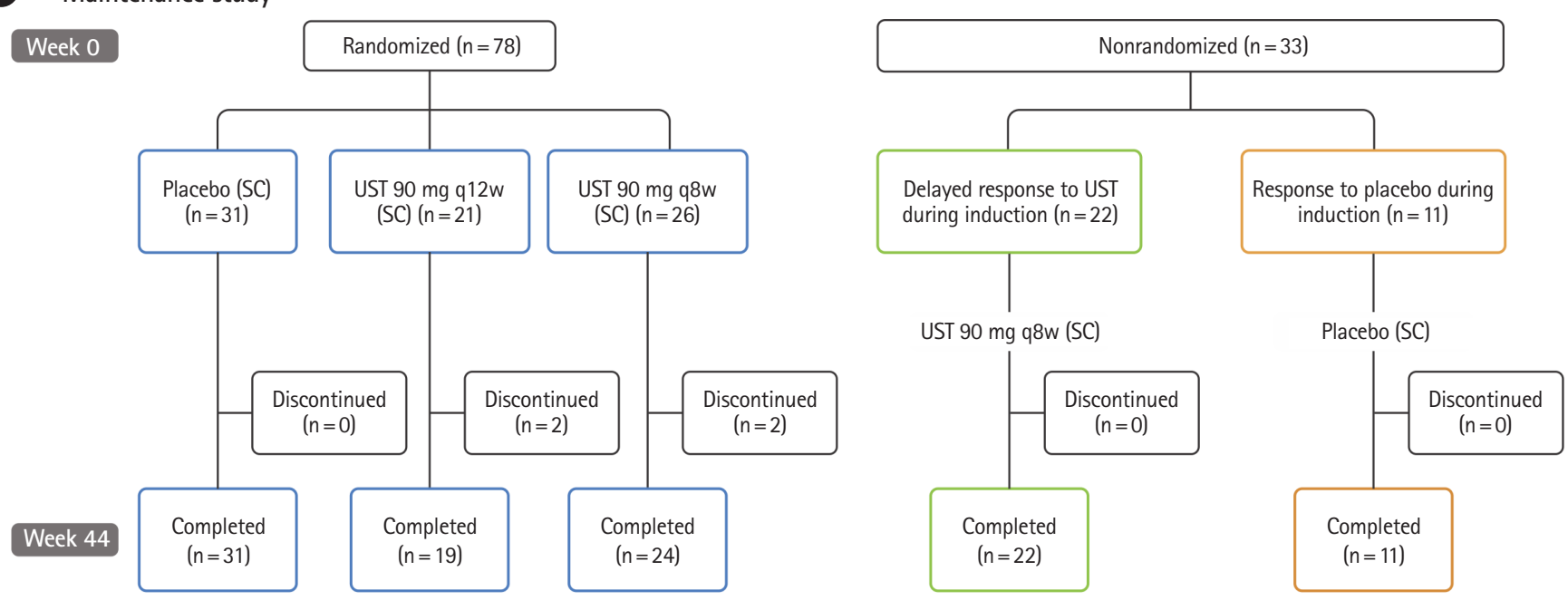

Fig. 1. Study design and patient disposition. (A) Induction study and (B) maintenance study. UST, ustekinumab; SFU, safety follow-up; IV, intravenous; SC, subcutaneous; q12W, every 12 weeks; q8w, every 8 weeks.

compared to those who had a history of biologic failure (Supplementary Table 1).

Among 29 patients who randomized to receive IV UST at week 0 and did not have a response by week $8,9 / 29(31.0 \%)$ patients had a clinical response and 1/29 (3.4\%) achieved clinical remission by week 16 .

\section{Maintenance Therapy}

In the East-Asian subpopulation, among patients who showed a clinical response to induction therapy with UST, clinical remission at week 44 was $47.6 \%$ (10/21 patients) in the UST 90 mg q12w, 19.2\% (5/26 patients) in the UST $90 \mathrm{mg}$ q8w, and a numerically higher proportion of patients in the UST $90 \mathrm{mg}$ q12w group compared to the placebo group (22.6\%, 7/31 patients) (Fig. 3, Supplementary Table 2). The relative change in clinical remission rates from maintenance baseline to week 44 was numerically higher in both UST groups $(233.3 \%$ in the UST $90 \mathrm{mg}$ q8w group and $66.7 \%$ in the UST $90 \mathrm{mg} \mathrm{q12w}$ group) compared to placebo group (-12.5\%). Logistic regression analysis results showed that clinical remission at maintenance baseline was the only stratification variable for which the $95 \%$ CI did not cross 1 (Supplementary Table 3). Among those with clinical remission at week 0 of the maintenance study, 2/3 (66.7\%) patients in the UST $90 \mathrm{mg}$ q12w group, 1/3 (33.3\%) patients in the UST $90 \mathrm{mg}$ q8w group, and 3/8 (37.5\%) in the placebo group maintained clinical remission through week 44 


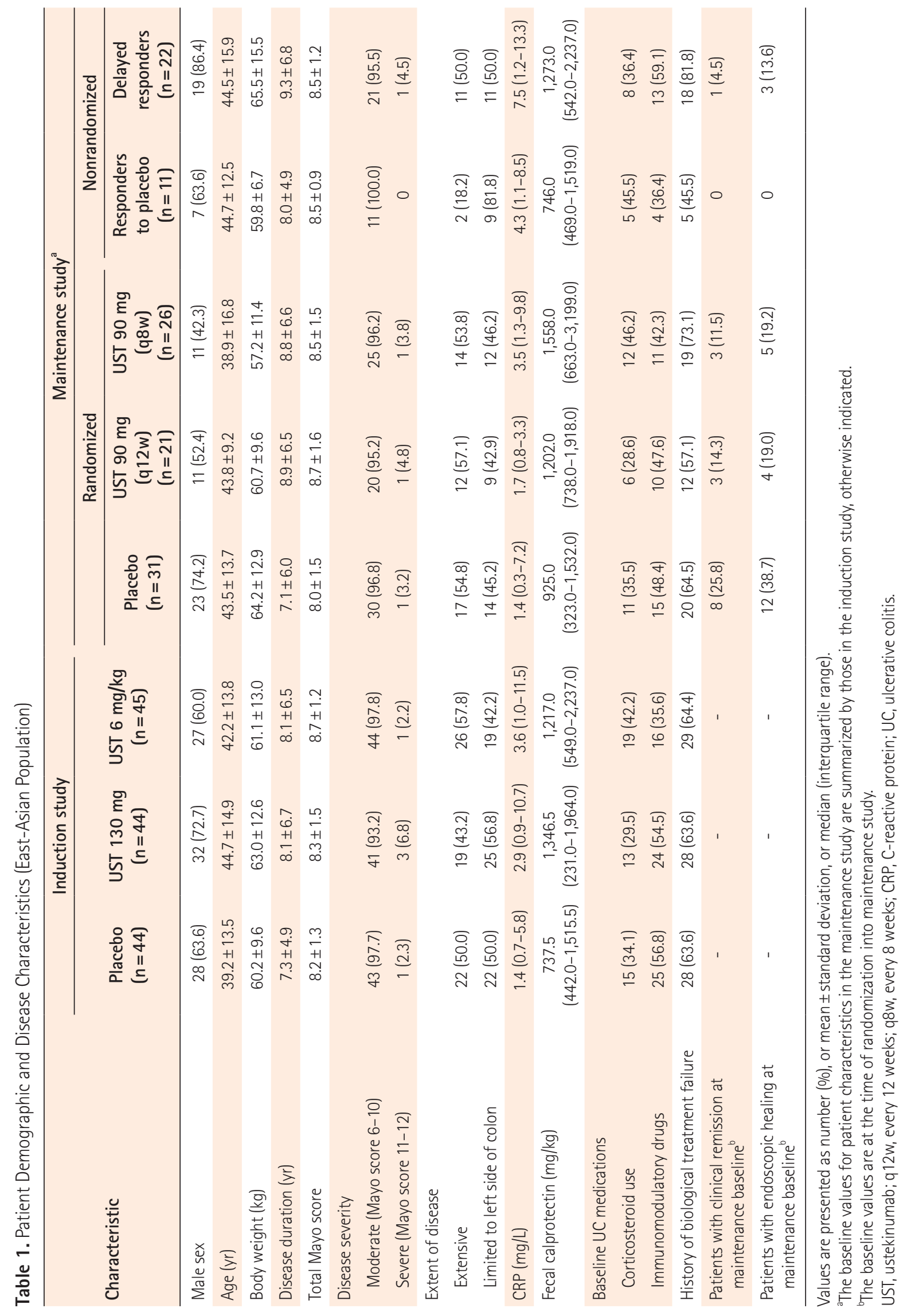



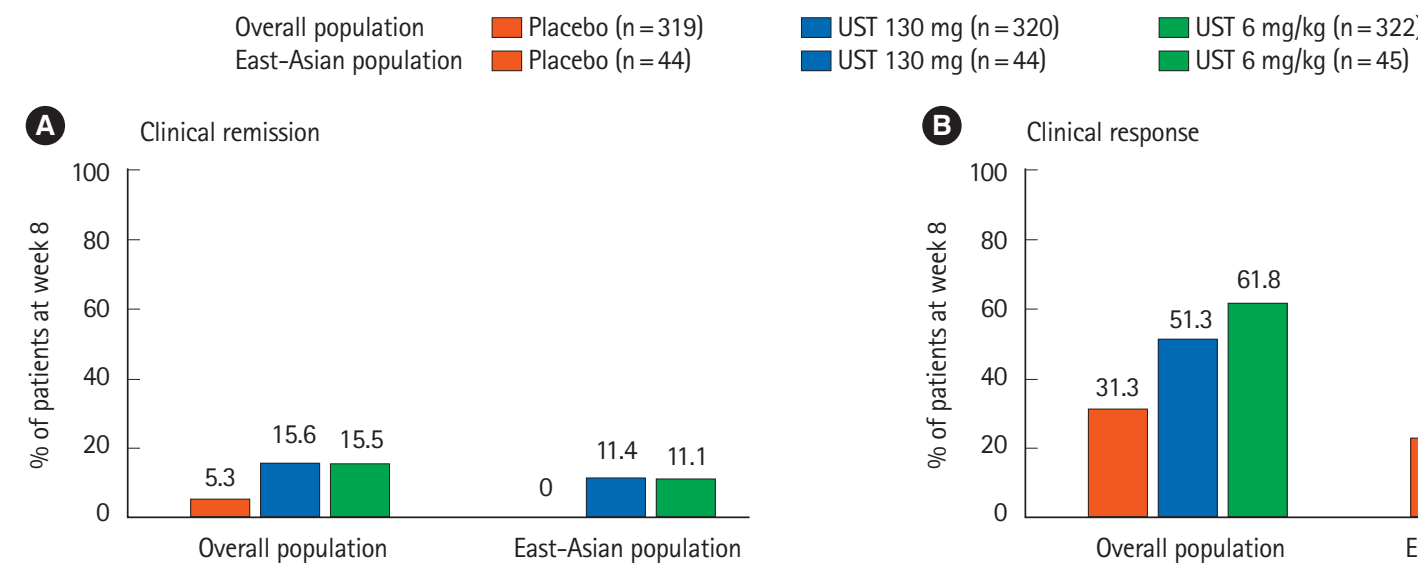

UST $130 \mathrm{mg}(\mathrm{n}=44) \quad \square$ UST $6 \mathrm{mg} / \mathrm{kg}(\mathrm{n}=45)$
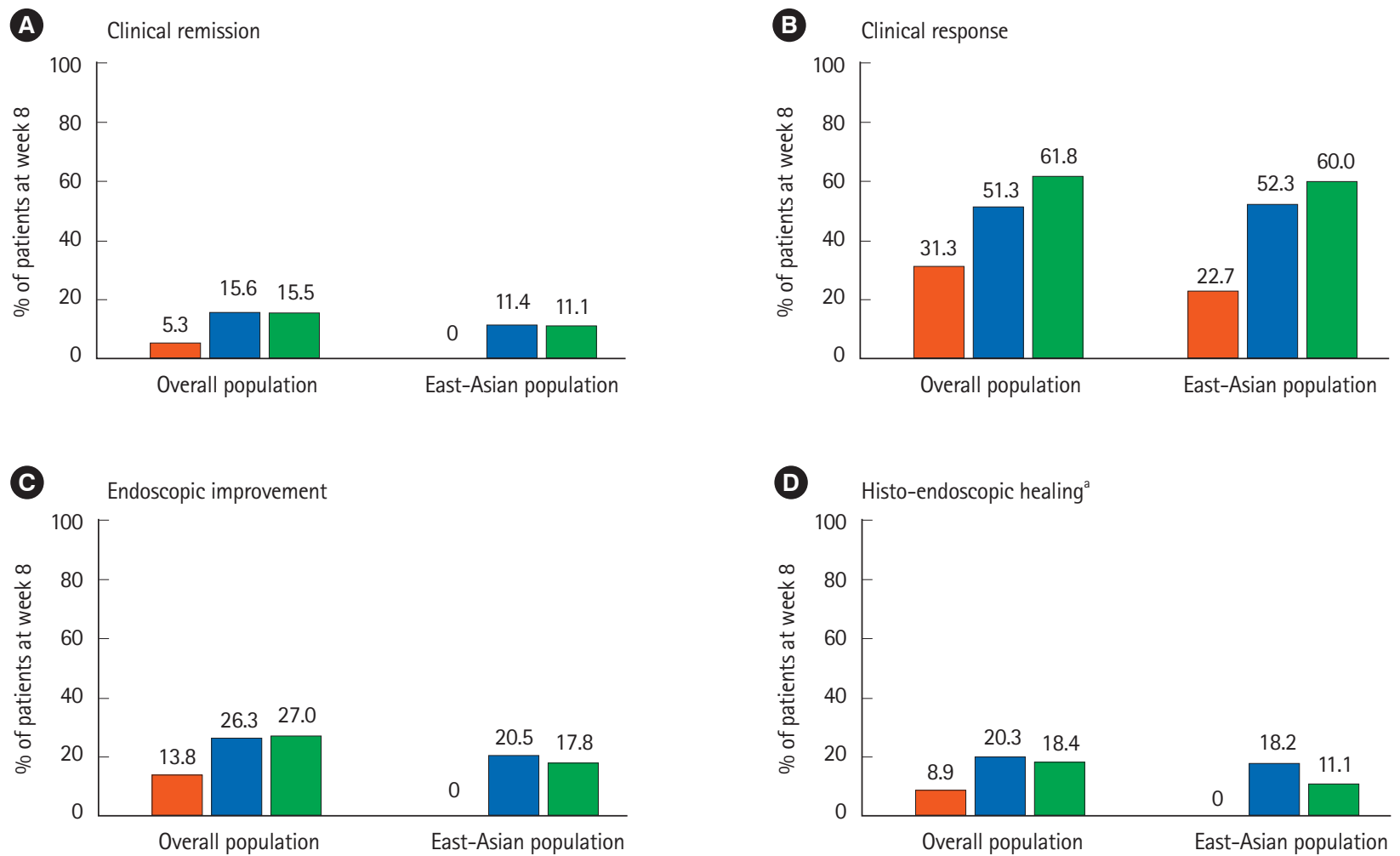

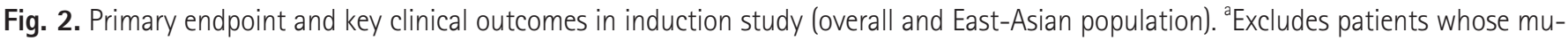
cosal healing statues cannot be determined at week 8 due to an unevaluable biopsy (i.e., a biopsy that was collected, but could not be assessed due to sample preparation or technical errors). Overall population: $n=316,316,315$ and East-Asian population: $n=44,44$, and 45 for placebo, ustekinumab (UST) $130 \mathrm{mg}$ and UST $6 \mathrm{mg} / \mathrm{kg}$, respectively.

(Fig. 3).

A numerically greater proportion of East-Asian patients receiving UST $90 \mathrm{mg} \mathrm{q12w}(16 / 21,76.2 \%)$ and UST $90 \mathrm{mg} \mathrm{q8w}$ (12/26, 46.2\%) maintained clinical response through week 44 compared to those receiving placebo $(11 / 31,35.5 \%)$. Similar patterns were observed for endoscopic improvement, corticosteroid-free remission, and histo-endoscopic mucosal healing (Fig. 3, Supplementary Table 2).

Improvement in partial Mayo score observed at maintenance baseline was maintained in the UST groups through week 44 . The proportion of patients in the UST q12w group in partial Mayo remission and symptomatic remission was maintained through week 44, while the proportion of patients in the placebo group who achieved partial Mayo remission and symptomatic remission decreased over time through week 44 . The proportion of patients in the UST q8w group in partial Mayo remission and symptomatic remission decreased slightly toward week 8 but was generally maintained through week 44 there- after (Supplementary Fig. 3). Median IBDQ scores at week 44 were maintained in the UST q12w group and slightly decreased in the UST q8w group, while they decreased considerably in the placebo group (Supplementary Table 2). Concentrations of F-CP decreased in the UST $90 \mathrm{mg}$ q12w group and were maintained in the UST $90 \mathrm{mg}$ q8w group through week 44, but increased in placebo. The CRP concentrations were maintained in both the UST groups but increased in the placebo group through week 44 (Supplementary Fig. 3). More patients who were naïve to biologic therapy or did not have a history of biologic failure, had numerically higher clinical remission and clinical response at week 44 compared to those who had a history of biologic failure (Supplementary Table 2).

Among patients who had delayed response to UST in induction study, 2/22 (9.1\%) patients achieved clinical remission at week 44 and 14/22 (63.6\%) patients maintained clinical response through week 44 in the maintenance study. 

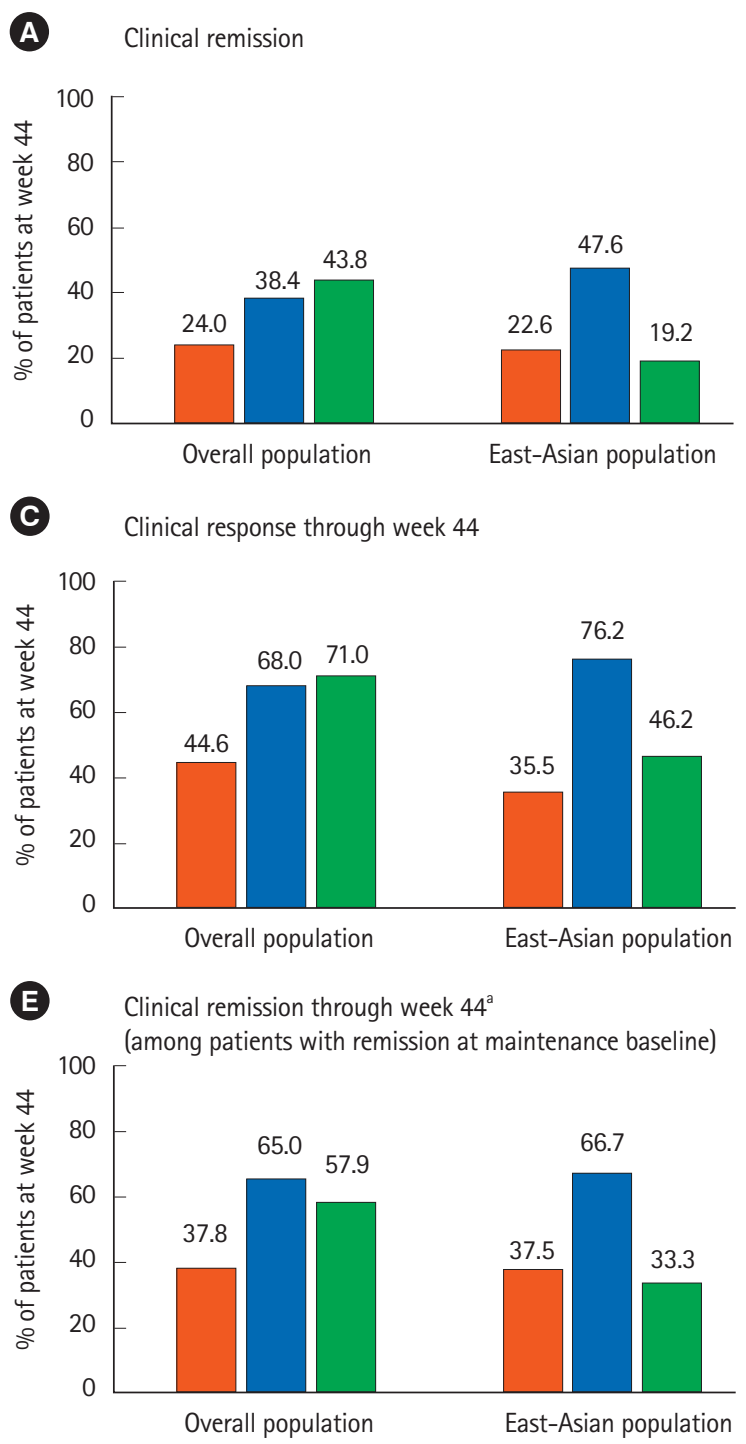

B Endoscopic improvement

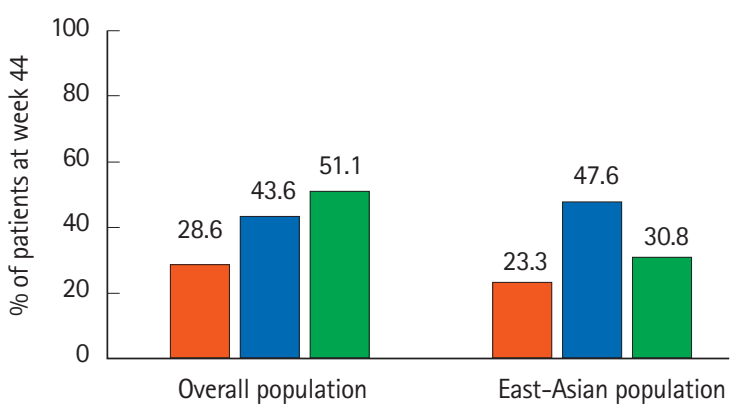

D Corticosteroid-free remission

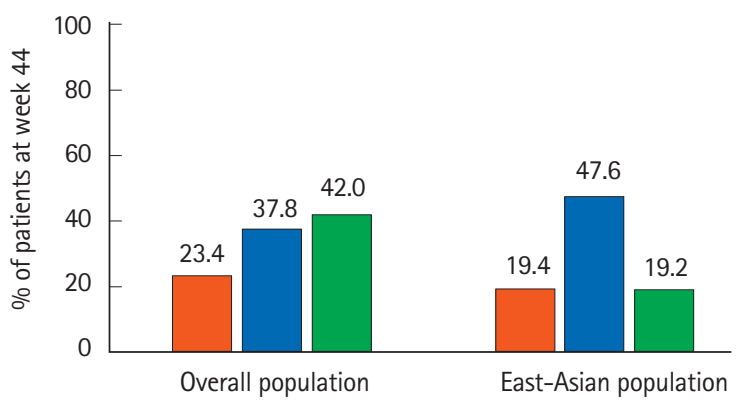

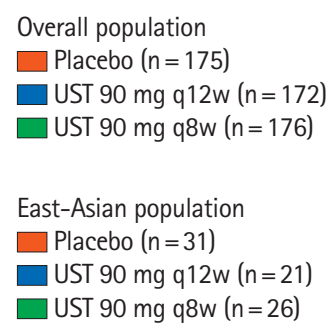

Fig. 3. Primary and major secondary endpoints in maintenance study (overall and East-Asian population). ${ }^{2}$ Analyzed among patients with remission at maintenance baseline. Overall population: $n=45,40,38$ and East-Asian population: $n=8,3$, and 3 for placebo, ustekinumab (UST) 90 mg every 12 weeks (q12w) and UST 90 mg every 8 weeks (q8w), respectively.

\section{Safety}

Through week 8 of induction, AEs in East-Asian patients were reported in 19/44 (43.2\%) in the UST $130 \mathrm{mg}, 21 / 45(46.7 \%)$ in the UST $6 \mathrm{mg} / \mathrm{kg}$ and 18/44 (40.9\%) patients in the placebo group (Table 2). Commonly reported AEs occurring in $>5 \%$ of patients in any group included viral upper respiratory tract infections and headache. One patient who received UST $130 \mathrm{mg}$ at week 0 had a serious AE of gastroenteritis. No malignancies were reported in the East-Asian population through week 8 in the induction study.

Among patients who were re-randomized in the maintenance study, the percentage of patients with $\geq 1$ AEs in the random- ized UST 90 mg q8w, UST 90 mg q12w, and placebo groups was $73.1 \%, 81.0 \%$, and $90.3 \%$ through week 44 in the maintenance study, respectively (Table 2). Six patients who received UST treatment in the maintenance study had a serious AE (the UST $90 \mathrm{mg}$ q12w group, $\mathrm{n}=1$ [enteritis]; the UST $90 \mathrm{mg}$ q8w group, $\mathrm{n}=5$ [2 cases of UC, a case of colon cancer and dermatitis, rectal adenoma, and pyrexia]). One patient in the UST 90 mg q8w group was diagnosed with colon cancer at day 2 of maintenance study, however, this event was not considered by the investigator to be study drug-related.

In the maintenance study, only one patient in the placebo group experienced injection-site reaction (Table 2). 


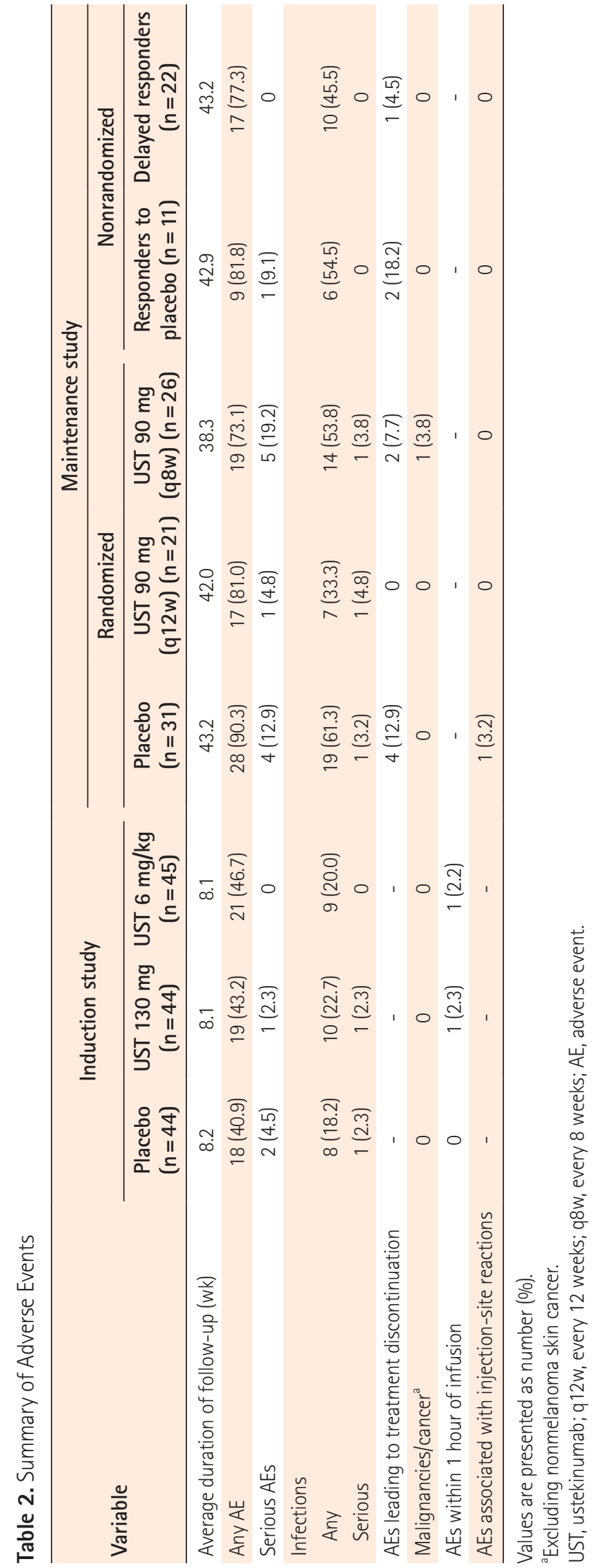

There were no deaths reported in the East-Asian population during the induction or maintenance studies, nor any cases of opportunistic infection, tuberculosis, or cardiovascular events.

\section{Pharmacokinetics and Immunogenicity}

In the induction as well as the maintenance study, the serum concentrations of UST in the East-Asian patients were generally comparable with those observed in non-Asian patients (Supplementary Fig. 4). Dose dependent serum concentrations of UST were observed in East-Asian patients in the induction study (median concentrations were 42.77 and 120.07 $\mu \mathrm{g} / \mathrm{mL}$ at 1 -hour post-dose on week 0 , and 2.28 and $5.80 \mu \mathrm{g} / \mathrm{mL}$ at week 8 for UST $130 \mathrm{mg}$ and UST $6 \mathrm{mg} / \mathrm{kg}$, respectively). In East-Asian patients in the maintenance study, higher serum trough concentrations of UST at steady state were observed for UST $90 \mathrm{mg}$ q8w compared to those for UST $90 \mathrm{mg}$ q12w (median concentrations were 2.36 to $2.99 \mu \mathrm{g} / \mathrm{mL}$ compared to 0.86 to $0.88 \mu \mathrm{g} / \mathrm{mL}$ ) (Supplementary Fig. 4). Among EastAsian patients with appropriate samples, 2/117 (1.7\%) patients (UST $130 \mathrm{mg}, \mathrm{n}=1$; UST $6 \mathrm{mg} / \mathrm{kg}, \mathrm{n}=1$ ) were positive for antibodies to UST through induction week 8 . Through week 44 of maintenance, 5 out of $100(5.0 \%)$ patients who were in clinical response with IV UST during induction study were randomized to each group (placebo, $\mathrm{n}=3$; UST $90 \mathrm{mg} \mathrm{q12w}, \mathrm{n}=1$; UST $90 \mathrm{mg} \mathrm{q} 8 \mathrm{w}, \mathrm{n}=1$ ) were positive for antibodies to UST. Of the 5 treated patients who were positive for antibodies to UST, $4 / 5$ $(80 \%)$ were positive for neutralizing antibodies.

\section{DISCUSSION}

This post hoc analysis of UNIFI demonstrated the efficacy of UST induction and maintenance therapies in East-Asian patients with moderately to severely active UC.

Similar trends of efficacy were observed between the overall and East-Asian populations in the induction study. While the robust efficacy of UST $90 \mathrm{mg}$ q8w as maintenance therapy was confirmed across the majority endpoints in the overall population, and consistent efficacy was observed with UST 90 mg q12w group between the overall population and East-Asian population, several limitations may have impacted on the interpretation of efficacy data for UST $90 \mathrm{mg}$ q8w in East-Asian population in the maintenance study. There was some imbalance for disease activities at induction baseline among patients who were randomized to the maintenance study, primarily due to the limited number of East-Asian patients and the lack of stratification by region (Eastern Europe, Asia and rest of 
world) in the maintenance study. This might affect the induction efficacy and result in the imbalance that fewer patients in both UST groups achieved remission at maintenance baseline, especially in the $\mathrm{q} 8 \mathrm{w}$ group compared with the placebo group in the East-Asian population.

Logistic regression analysis for clinical remission at week 44 using the stratification variables suggested that clinical remission status (yes or no) at the maintenance baseline might have an impact on the clinical remission at week 44 , however, other stratification variables did not have any impact. Therefore, such imbalance might be one of the reasons for the lack of differences in clinical remission at week 44 between the UST q8w and placebo groups. Importantly, all other clinical outcomes (e.g., maintenance of clinical response, endoscopic improvement, symptomatic remission and mean change from baseline in partial Mayo score), inflammatory markers such as CRP, and health-related quality of life measures such as IBDQ showed numerically greater improvement in the q8w group compared with the placebo group. Of note, for the delayed responders in East-Asian population showed a similar trend for a lower proportion of patients who achieved clinical remission by UST induction treatment at maintenance baseline (Table 1) and by UST maintenance treatment at week 44 (Supplementary Table 2).

Moreover, trends for numerically greater improvement was observed in the $\mathrm{q} 12 \mathrm{w}$ group compared to the $\mathrm{q} 8 \mathrm{w}$ group in the East-Asian population across several endpoints. It may be due to the different trends between the UST groups observed only in the East-Asian population until week 8 of the maintenance study, even though treatment regimens were identical until week 8 for both UST groups. While the proportion of patients who achieved symptomatic remission was increased in the UST $90 \mathrm{mg} \mathrm{q12w}$ group up to week 8 of the maintenance study, but it was decreased in the UST $90 \mathrm{mg}$ q8w group (Supplementary Fig. 3). Despite the initial decrease, UST $90 \mathrm{mg}$ q8w treatment maintained symptomatic remission through week 44; however, continuous decrease in the proportion of subjects in symptomatic remission was observed in the placebo group over time thereafter. No single background factor was identified to explain such different trends, but there may be several potential differences in patient characteristics be-

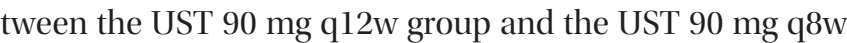
group, which may have an impact on the interpretation of the results.

The efficacy profile of UST in East-Asian patients with or without failure of previous biologic treatments was generally simi- lar to what was observed in the overall population. ${ }^{29}$

PK assessment showed that the serum concentrations of UST in the East-Asian patients were generally comparable with those observed in non-Asian patients. The incidence of immunogenicity was relatively low in the overall and East-Asian populations.

Analyses suggested that there are no meaningful differences among the UST and placebo treatment groups in the overall safety profile for either induction treatment (UST $130 \mathrm{mg}$ IV and $6 \mathrm{mg} / \mathrm{kg} \mathrm{IV}$ ) or maintenance treatment (UST $90 \mathrm{mg} \mathrm{SC}$ q8w and q12w) through 1 year. The overall safety profile observed in the East-Asian population in this study is consistent with that in the overall population as well as the known safety profile of UST observed in the previous UST programs.

Overall, UST induction and maintenance therapy was demonstrated to be effective in East-Asian patients with moderately to severely active UC. The efficacy, safety, pharmacokinetics and immunogenicity profile observed in the East-Asian population was generally consistent with that in the overall population.

\section{ADDITIONAL INFORMATION}

\section{Funding Source}

This study was funded by Janssen Research \& Development, LLC, Spring House, PA, USA and Janssen Pharmaceutical K.K., Tokyo, Japan.

\section{Conflict of Interest}

Hisamatsu T has received joint research support from Alfresa Pharma Co. Ltd; grant support from Mitsubishi Tanabe Pharma Corporation, EA pharma Co. Ltd., AbbVie GK, JIMRO Co. Ltd., Zeria Pharmaceutical Co. Ltd., Daiichi-Sankyo, Kyorin Pharmaceutical Co. Ltd., Nippon Kayaku Co. Ltd., Astellas Pharma Inc., Takeda Pharmaceutical Co. Ltd., Pfizer Inc., Mochida Pharmaceutical Co., Ltd.; consulting fee from EA pharma Co. Ltd., AbbVie GK, Celgene K.K., Janssen Pharmaceutical K.K., Pfizer Inc., Nichi-Iko Pharmaceutical Co., Ltd.; and lecture fee from Mitsubishi Tanabe Pharma Corporation, $\mathrm{Ab}$ bVie GK, EA pharma Co. Ltd., Kyorin Pharmaceutical Co. Ltd., JIMRO Co., Janssen Pharmaceutical K.K., Mochida Pharmaceutical Co., Ltd., Takeda Pharmaceutical Co. Ltd. Motoya S has received grant support from EA pharma Co. Ltd., AbbVie GK, Takeda Pharmaceutical Co. Ltd., Pfizer Inc. and lecture fee from Mitsubishi Tanabe Pharma Corporation, Takeda Pharmaceutical Co. Ltd., Suzuki Y has received honoraria from Ab- 
bVie, Mitsubishi Tanabe Pharma, ZERIA, Mochida Pharmaceutical Co. Ltd., Kyorin Pharmaceutical Co. Ltd., EA Pharma Co. Ltd., and commercial research funding from AbbVie, Mitsubishi Tanabe Pharma, EA Pharma Co. Ltd., JIMRO Co. Ltd., Mochida Pharmaceutical Co. Ltd., KISSEI, Nippon Kayaku. Ohnishi Y has received grant support from AbbVie GK. Fujii $\mathrm{N}$, Matsushima N, and Zheng $\mathrm{R}$ are employees of Janssen Pharmaceutical K.K. Marano CW is an employee of Janssen R\&D LLC, USA. Authors received the editorial support from SIRO Clinpharm Pvt. Ltd funded by Janssen Pharmaceutical K.K. Kim HJ has no conflict of interest to declare.

\section{Author Contribution}

Conceptualization: Hisamatsu T, Marano CW. Formal analysis: Fujii N, Matsushima N, Zheng R, Marano CW. Investigation: Hisamatsu T, Kim HJ, Motoya S, Suzuki Y, Ohnishi Y. Methodology: Fujii N, Matsushima N, Zheng R, Marano CW. Project administration: Fujii N. Visualization: Fujii N. Writing - original draft: Fujii N. Writing - review \& editing: all authors. Approval of final manuscript: all authors.

Hisamatsu T was an investigator in the UNIFI Global Steering Committee. Kim HJ, Motoya S, Suzuki Y, and Ohnishi Y were investigators in the current study.

\section{Others}

The authors thank the study participants without whom this study would not have been accomplished, and also thank the investigators and study coordinators for their contributions to this study. Anupama Singh, SIRO Clinpharm Pvt. Ltd., provided medical writing assistance and Akino Tanaka, Janssen Pharmaceutical K.K., provided additional editorial support for this manuscript. Hiroki Yoshida (ex-employee of Janssen Pharmaceutical K.K.) provided statistical advice for this manuscript.

\section{ORCID}

Hisamatsu T https://orcid.org/0000-0002-1178-3536 Kim HJ Motoya S

Suzuki Y

Ohnishi Y

Fujii N

Matsushima N

Zheng R

Marano CW https://orcid.org/0000-0002-8761-5571 https://orcid.org/0000-0002-4194-8493 https://orcid.org/0000-0002-9813-9793 https://orcid.org/0000-0002-0150-3836 https://orcid.org/0000-0001-9758-8506 https://orcid.org/0000-0002-6967-6741 https://orcid.org/0000-0001-6242-2012 https://orcid.org/0000-0002-4965-5142

\section{Supplementary Material}

Supplementary materials are available at the Intestinal Research website (https://www.irjournal.org).

\section{REFERENCES}

1. Stenson WF. Inflammatory bowel disease. In: Goldman l, Bennett JC, eds. Cecil textbook of medicine. 21st ed. Philadelphia: WB Saunders Co., 2000;722-729.

2. Ng SC. Emerging trends of inflammatory bowel disease in Asia. Gastroenterol Hepatol (N Y) 2016;12:193-196.

3. Murakami Y, Nishiwaki Y, Oba MS, et al. Estimated prevalence of ulcerative colitis and Crohn's disease in Japan in 2014: an analysis of a nationwide survey. J Gastroenterol 2019;54:10701077.

4. World Gastroenterology Organisation (WGO). WGO handbook on inflammatory bowel disease (IBD): navigating evolving therapies in an evolving disease. Milwaukee: WGO, 2017.

5. Ng WK, Wong SH, Ng SC. Changing epidemiological trends of inflammatory bowel disease in Asia. Intest Res 2016;14:111119.

6. Kim HJ, Hann HJ, Hong SN, et al. Incidence and natural course of inflammatory bowel disease in Korea, 2006-2012: a nationwide population-based study. Inflamm Bowel Dis 2015;21:623630.

7. Choi CH, Jung SA, Lee BI, et al. Diagnostic guideline of ulcerative colitis. Korean J Gastroenterol 2009;53:145-160.

8. Kornbluth A, Sachar DB; Practice Parameters Committee of the American College of Gastroenterology. Ulcerative colitis practice guidelines in adults: American College of Gastroenterology, Practice Parameters Committee. Am J Gastroenterol 2010;105:501-523.

9. Magro F, Gionchetti P, Eliakim R, et al. Third European evidencebased consensus on diagnosis and management of ulcerative colitis. Part 1: definitions, diagnosis, extra-intestinal manifestations, pregnancy, cancer surveillance, surgery, and ileo-anal pouch disorders. J Crohns Colitis 2017;11:649-670.

10. Matsuoka K, Kobayashi T, Ueno F, et al. Evidence-based clinical practice guidelines for inflammatory bowel disease. J Gastroenterol 2018;53:305-353.

11. Rubin DT, Ananthakrishnan AN, Siegel CA, Sauer BG, Long MD. ACG clinical guideline: ulcerative colitis in adults. Am J Gastroenterol 2019;114:384-413.

12. Suzuki Y, Motoya S, Hanai H, et al. Efficacy and safety of adalimumab in Japanese patients with moderately to severely active ulcerative colitis. J Gastroenterol 2014;49:283-294. 
13. Motoya S, Watanabe K, Ogata H, et al. Vedolizumab in Japanese patients with ulcerative colitis: a phase 3 , randomized, double-blind, placebo-controlled study. PLoS One 2019;14: e0212989.

14. Motoya S, Watanabe M, Kim HJ, et al. Tofacitinib induction and maintenance therapy in East Asian patients with active ulcerative colitis: subgroup analyses from three phase 3 multinational studies. Intest Res 2018;16:233-245.

15. D'Haens GRAM, Lindsay JO, Panaccione R, Schreiber S. Ulcerative colitis: shifting sands. Drugs R D 2019;19:227-234.

16. Billioud V, Sandborn WJ, Peyrin-Biroulet L. Loss of response and need for adalimumab dose intensification in Crohn's disease: a systematic review. Am J Gastroenterol 2011;106:674684.

17. Gisbert JP, Panés J. Loss of response and requirement of infliximab dose intensification in Crohn's disease: a review. Am J Gastroenterol 2009;104:760-767.

18. Roblin X, Marotte H, Leclerc M, et al. Combination of C-reactive protein, infliximab trough levels, and stable but not transient antibodies to infliximab are associated with loss of response to infliximab in inflammatory bowel disease. J Crohns Colitis 2015;9:525-531.

19. Vincent FB, Morand EF, Murphy K, Mackay F, Mariette X, Marcelli C. Antidrug antibodies (ADAb) to tumour necrosis factor (TNF)-specific neutralising agents in chronic inflammatory diseases: a real issue, a clinical perspective. Ann Rheum Dis 2013;72:165-178.

20. Ordás I, Eckmann L, Talamini M, Baumgart DC, Sandborn WJ. Ulcerative colitis. Lancet 2012;380:1606-1619.

21. Sandborn WJ, Su C, Sands BE, et al. Tofacitinib as induction and maintenance therapy for ulcerative colitis. N Engl J Med 2017;376:1723-1736.

22. Sands BE, Feagan BG, Rutgeerts P, et al. Effects of vedolizum- ab induction therapy for patients with Crohn's disease in whom tumor necrosis factor antagonist treatment failed. Gastroenterology 2014;147:618-627.

23. Bonovas S, Fiorino G, Allocca M, et al. Biologic therapies and risk of infection and malignancy in patients with inflammatory bowel disease: a systematic review and network meta-analysis. Clin Gastroenterol Hepatol 2016;14:1385-1397.

24. Konidari A, Matary WE. Use of thiopurines in inflammatory bowel disease: safety issues. World J Gastrointest Pharmacol Ther 2014;5:63-76.

25. Rutgeerts PJ. Review article: the limitations of corticosteroid therapy in Crohn's disease. Aliment Pharmacol Ther 2001;15: 1515-1525.

26. Lichtenstein GR, Rutgeerts P, Sandborn WJ, et al. A pooled analysis of infections, malignancy, and mortality in infliximaband immunomodulator-treated adult patients with inflammatory bowel disease. Am J Gastroenterol 2012;107:1051-1063.

27. Hibi T, Imai Y, Murata Y, Matsushima N, Zheng R, Gasink C. Efficacy and safety of ustekinumab in Japanese patients with moderately to severely active Crohn's disease: a subpopulation analysis of phase 3 induction and maintenance studies. Intest Res 2017;15:475-486.

28. Feagan BG, Sandborn WJ, Gasink C, et al. Ustekinumab as induction and maintenance therapy for Crohn's disease. N Engl J Med 2016;375:1946-1960.

29. Sands BE, Sandborn WJ, Panaccione R, et al. Ustekinumab as induction and maintenance therapy for ulcerative colitis. $\mathrm{N}$ Engl J Med 2019;381:1201-1214.

30. D'Haens G, Sandborn WJ, Feagan BG, et al. A review of activity indices and efficacy end points for clinical trials of medical therapy in adults with ulcerative colitis. Gastroenterology 2007; 132:763-786. 


\section{See "Efficacy and safety of ustekinumab in East Asian patients with moderately to severely active ulcerative colitis: a} subpopulation analysis of global phase 3 induction and maintenance studies (UNIFI)" on page 386-397.

Supplementary Table 1. Other Efficacy Endpoints in the Induction Study (Overall and East-Asian Population; Assessment at Week 8 and at Week 16)

\begin{tabular}{|c|c|c|c|c|c|c|}
\hline \multirow[b]{2}{*}{ At week 8} & \multicolumn{3}{|c|}{ Overall population } & \multicolumn{3}{|c|}{ East-Asian population } \\
\hline & $\begin{array}{l}\text { Placebo } \\
(n=319)\end{array}$ & $\begin{array}{l}\text { UST } 130 \mathrm{mg} \\
(\mathrm{n}=320)\end{array}$ & $\begin{array}{l}\text { UST } 6 \mathrm{mg} / \mathrm{kg} \\
(\mathrm{n}=322)\end{array}$ & $\begin{array}{l}\text { Placebo } \\
(n=44)\end{array}$ & $\begin{array}{l}\text { UST } 130 \mathrm{mg} \\
\quad(n=44)\end{array}$ & $\begin{array}{l}\text { UST } 6 \mathrm{mg} / \mathrm{kg} \\
\quad(\mathrm{n}=45)\end{array}$ \\
\hline Histologic improvement, ${ }^{\text {a }}$ (\%) & $65(21.9)$ & $113(37.9)$ & $105(35.6)$ & $5(11.6)$ & $13(30.2)$ & $16(36.4)$ \\
\hline Symptomatic remission, n (\%) & $72(22.6)$ & $132(41.3)$ & $144(44.7)$ & $13(29.5)$ & 19 (43.2) & $20(44.4)$ \\
\hline $\begin{array}{l}\text { IBDQ, change from baseline to week } 8, \\
\text { median (IQR) }\end{array}$ & $10.0(-2.0 ; 34.0)$ & $31.5(7.5 ; 53.5)$ & $31.0(11.0 ; 56.0)$ & $5.0(-8.0 ; 15.0)$ & $25.5(8.0 ; 43.0)$ & $26.0(12.0 ; 50.0)$ \\
\hline \multicolumn{7}{|l|}{ Efficacy by biologic failure status } \\
\hline Prior biologic failure, $n$ & 161 & 164 & 166 & 28.0 & 28 & 29 \\
\hline Clinical remission, n (\%) & $2(1.2)$ & 19 (11.6) & $21(12.7)$ & 0 & $2(7.1)$ & $3(10.3)$ \\
\hline Clinical response, n (\%) & $44(27.3)$ & $74(45.1)$ & $95(57.2)$ & $5(17.9)$ & $14(50.0)$ & $15(51.7)$ \\
\hline Biologic naïve or no biologic failure, $n$ & 158 & 156 & 156 & 16.0 & 16 & 16 \\
\hline Clinical remission, n (\%) & $15(9.5)$ & $31(19.9)$ & $29(18.6)$ & 0 & $3(18.8)$ & $2(12.5)$ \\
\hline Clinical response, n (\%) & $56(35.4)$ & $90(57.7)$ & $104(66.7)$ & $5(31.3)$ & $9(56.3)$ & $12(75.0)$ \\
\hline At week 16 & $\begin{array}{c}\text { Placebo IV } \\
(\mathrm{I}-0) \rightarrow \\
\text { UST } 6 \mathrm{mg} / \mathrm{kg} \\
\text { IV (I-8) }\end{array}$ & $\begin{array}{l}\text { UST } 130 \mathrm{mg} \\
\text { IV (I-0) } \rightarrow \\
\text { UST } 90 \mathrm{mg} \\
\text { SC (I-8) }\end{array}$ & $\begin{array}{l}\text { UST } 6 \mathrm{mg} / \mathrm{kg} \\
\text { IV }(\mathrm{I}-0) \rightarrow \\
\text { UST } 90 \mathrm{mg} \\
\text { SC (I-8) }\end{array}$ & $\begin{array}{c}\text { Placebo IV } \\
(\mathrm{I}-0) \rightarrow \text { UST } \\
6 \mathrm{mg} / \mathrm{kg} \\
\text { IV (I-8) }\end{array}$ & $\begin{array}{l}\text { UST } 130 \mathrm{mg} \\
\text { IV }(1-0) \rightarrow \\
\text { UST } 90 \mathrm{mg} \\
\text { SC (I-8) }\end{array}$ & $\begin{array}{l}\text { UST } 6 \mathrm{mg} / \mathrm{kg} \\
\text { IV (I-0) a } \rightarrow \\
\text { UST } 90 \mathrm{mg} \\
\text { SC (I-8) }\end{array}$ \\
\hline Placebo-responders/UST-nonresponders, n & 184 & 132 & 101 & 28 & 17 & 12 \\
\hline Clinical remission, n (\%) & $24(13.0)$ & $13(9.8)$ & $9(8.9)$ & $4(14.3)$ & 0 & $1(8.3)$ \\
\hline Clinical response, n (\%) & $119(64.7)$ & $60(45.5)$ & $42(41.6)$ & $11(39.3)$ & $5(29.4)$ & $4(33.3)$ \\
\hline Endoscopic improvement, n (\%) & $40(21.7)$ & $23(17.4)$ & $16(15.8)$ & $9(32.1)$ & $6(35.3)$ & $4(33.3)$ \\
\hline Histo-endoscopic healing, ${ }^{c}$ n (\%) & $30(16.5)$ & $13(10.0)$ & $15(14.9)$ & $5(17.9)$ & $3(18.8)$ & $2(16.7)$ \\
\hline
\end{tabular}

${ }^{a}$ Excludes patients with an unevaluable biopsy (i.e., a biopsy that was collected, but could not be assessed due to sample preparation or technical errors) at week 8. Overall population: $n=297,298$ and 295 and East-Asian population: $n=43,43$ and 44 for placebo, UST 130 mg and UST 6 mg/kg, respectively. ${ }^{b}$ Patients who had a prohibited change in concomitant UC medication or an ostomy or colectomy prior to the week 8 visit had their baseline value carried forward from the time of the event onward. Patients who had a missing IBDO score at week 8 had their last value carried forward. Overall population: $n=317,316$ and 321 and East-Asian population: $n=44,44$ and 45 for Placebo, UST $130 \mathrm{mg}$ and UST $6 \mathrm{mg} / \mathrm{kg}$, respectively.

'Excludes patients whose mucosal healing status cannot be determined at week 16 due to with an unevaluable biopsy (i.e., a biopsy that was collected, but could not be assessed due to sample preparation or technical errors). Note that patients who had an unevaluable biopsy at week 16 , but who did not achieve endoscopic healing, were considered not to have mucosal healing. Overall population: $n=182,130$ and 101 and East-Asian population: $n=28$, 16 and 12 for placebo, UST $130 \mathrm{mg}$ and UST $6 \mathrm{mg} / \mathrm{kg}$, respectively.

UST, ustekinumab; IBDQ, Inflammatory Bowel Disease Questionnaire; IQR, interquartile range; IV, intravenous; SC, subcutaneous; I-0, induction (week 0); $1-8$, induction (week 8). 


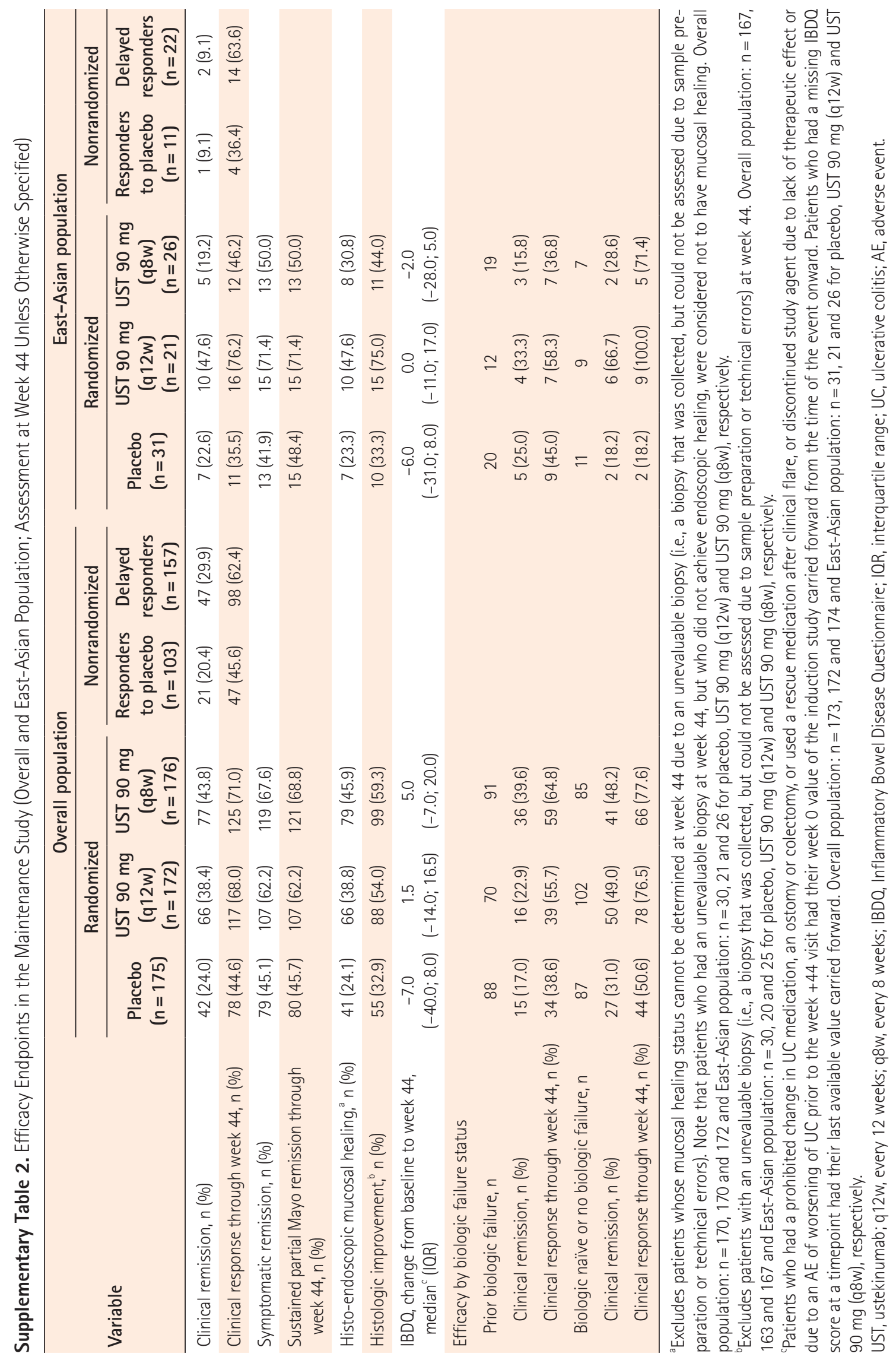


Supplementary Table 3. Odds Ratios for Clinical Remission Estimated by Logistic Regression ${ }^{a}$ Adjusted by Covariables in Maintenance Study (East-Asian Population)

\begin{tabular}{|c|c|c|c|}
\hline Stratification variable & $\begin{array}{c}\text { OR } \\
\text { estimate }\end{array}$ & $\begin{array}{l}\text { Lower } 95 \% \mathrm{CL} \\
\text { for } \mathrm{OR}\end{array}$ & $\begin{array}{l}\text { Upper } 95 \% \mathrm{CL} \\
\text { for } \mathrm{OR}\end{array}$ \\
\hline Status of clinical remission at the maintenance baseline & 6.938 & 1.941 & 24.798 \\
\hline Oral corticosteroid use (yes or no) at the maintenance baseline & 1.713 & 0.560 & 5.238 \\
\hline Induction treatment (Placebo IV to UST 6 mg/kg IV vs. UST 6 mg/kg IV) & 0.587 & 0.160 & 2.147 \\
\hline Induction treatment (UST 130 mg IV vs. UST 6 mg/kg IV) & 0.561 & 0.164 & 1.915 \\
\hline
\end{tabular}

${ }^{a} \mathrm{~A}$ logistic regression analysis model including fixed effect terms for treatment of maintenance phase and each stratification variable.

$\mathrm{CL}$, confidence limit; OR, odds ratio; IV, intravenous; UST, ustekinumab. 


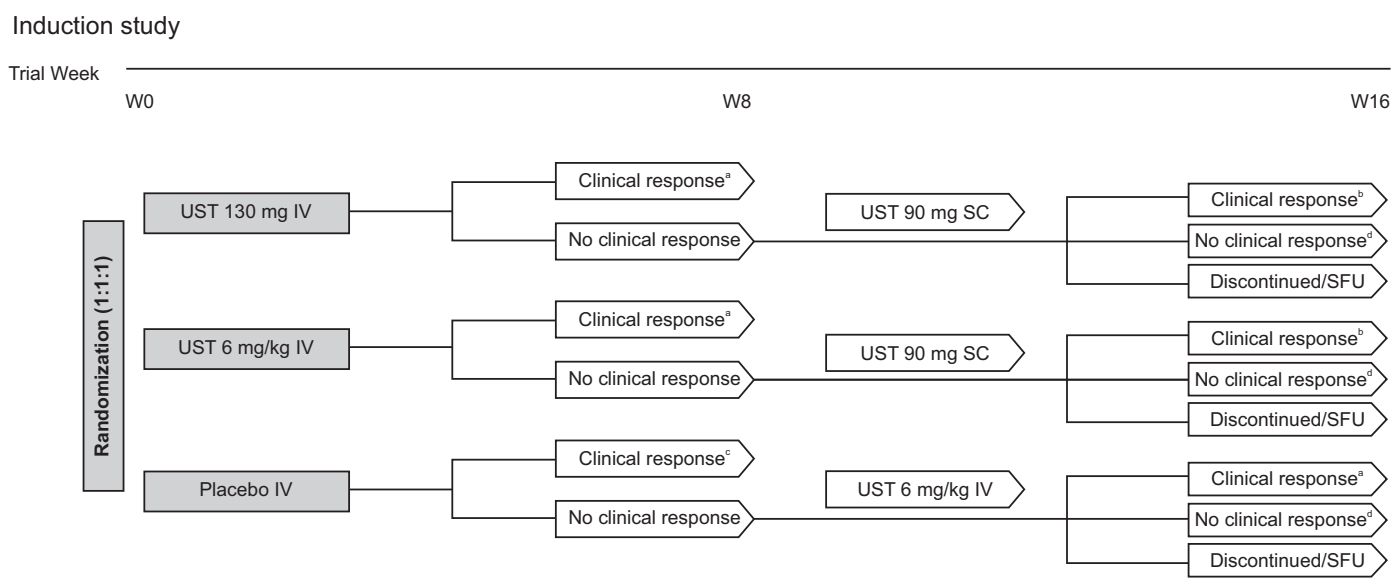

Maintenance study Trial Week

Maintenance WO

Maintenance W44
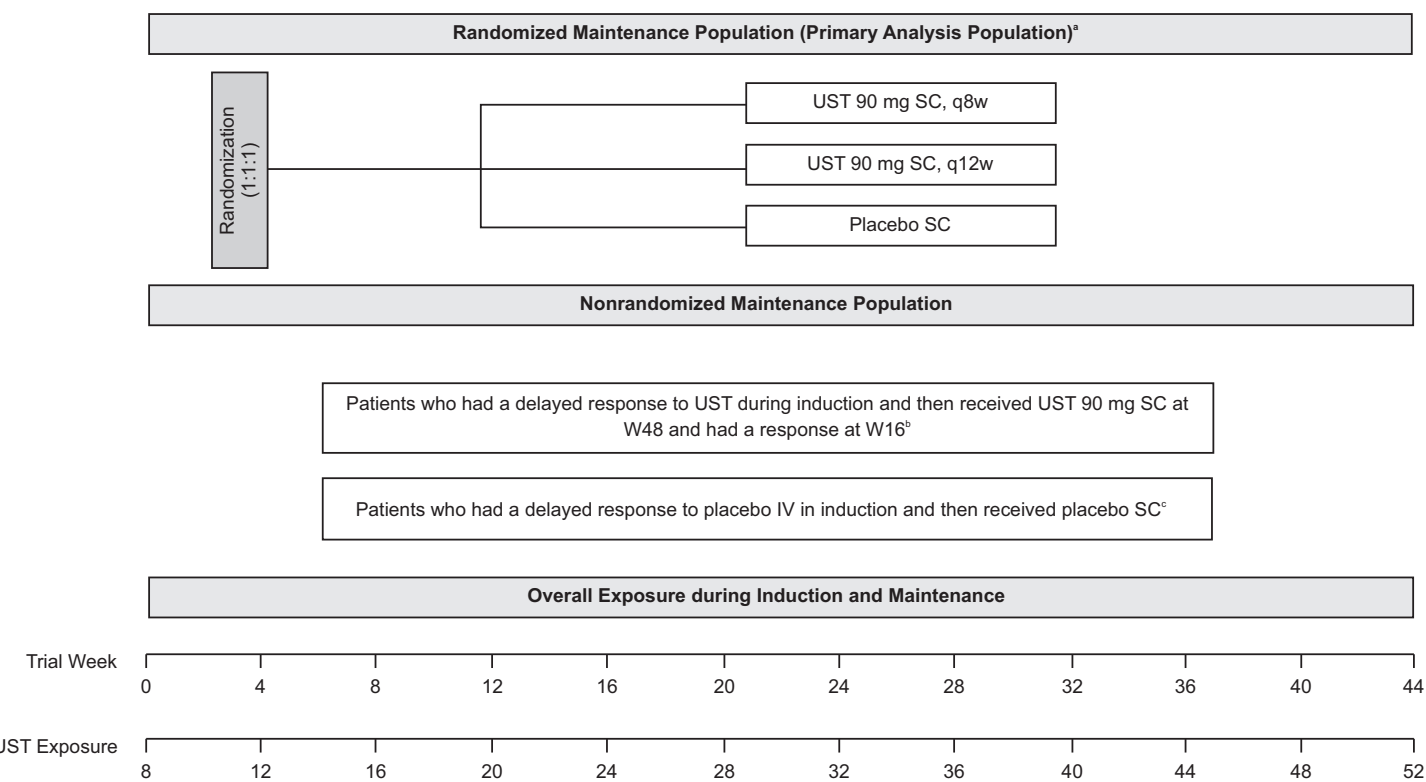

Supplementary Fig. 1. Overall study flow. ${ }^{a}$ Patients who had a response to UST IV at week 8 , as well as those who did not have a response to placebo IV and who then received UST $6 \mathrm{mg} / \mathrm{kg}$ IV at week 8 and had a response at week 16, made up the randomized primary analysis population in the maintenance study; Treatment of UST IV induction for non-responders at week 8 was blinded as patients received both an IV and SC administration with the allocation of active study drug dependent on the patient's original randomization. ${ }^{6} \mathrm{~Pa}-$ tients who had a delayed response to UST induction (nonresponders UST IV and who then received UST SC at week 8 and had a response at week 16) entered the maintenance study but did not undergo randomization. 'Patients who had a response to placebo IV in the induc-

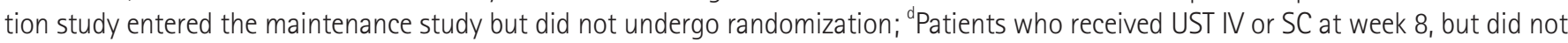
have a response at week 16 were discontinued from further participation and entered SFU per protocol. SFU extends 20 weeks after the last dose of UST or placebo. Baseline in the maintenance study is the same as week 8 or week 16 in the induction study, depending on when patients entered maintenance (week 8 or week 16). Overall exposure was 52 weeks or 60 weeks for patients who had a response to UST IV at week 8 or week 16 in the induction study and then completed through maintenance study, respectively. UST, ustekinumab; IV, intravenous; SC, subcutaneous; SFU, safety follow-up; q8w, every 8 weeks; q12W, every 12 weeks. 


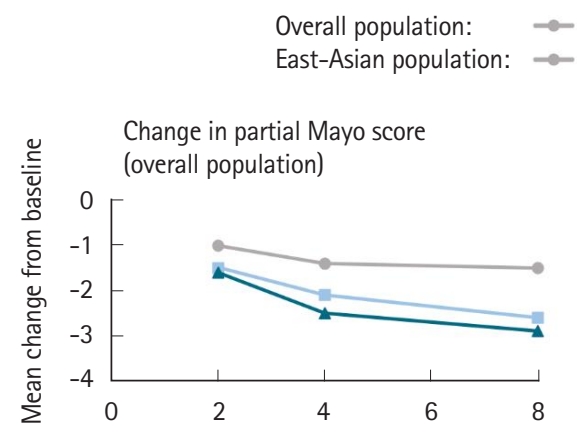
Placebo $(n=319)$
Placebo $(n=44)$

$=$ UST $130 \mathrm{mg}(n=320)$
$=$ UST $130 \mathrm{mg}(n=44)$

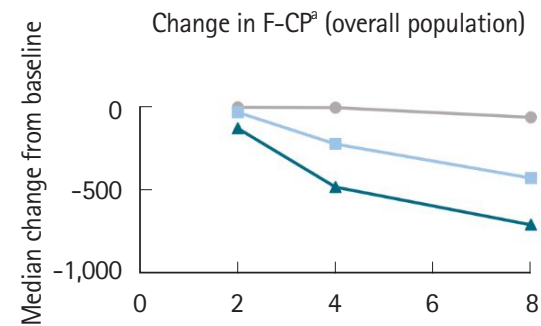

Change in $\mathrm{F}-\mathrm{CP}^{\mathrm{a}}$ (East-Asian population)

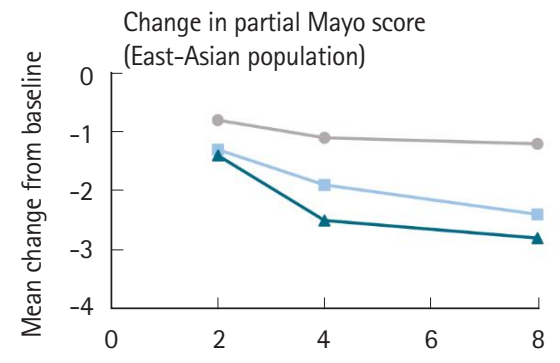

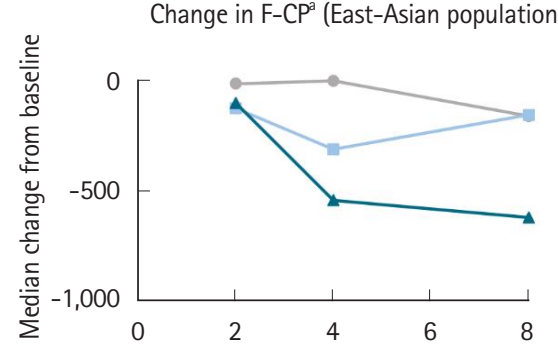

Duration (wk)

UST $6 \mathrm{mg} / \mathrm{kg}(\mathrm{n}=322)$

$\leadsto$ UST $6 \mathrm{mg} / \mathrm{kg}(\mathrm{n}=45)$
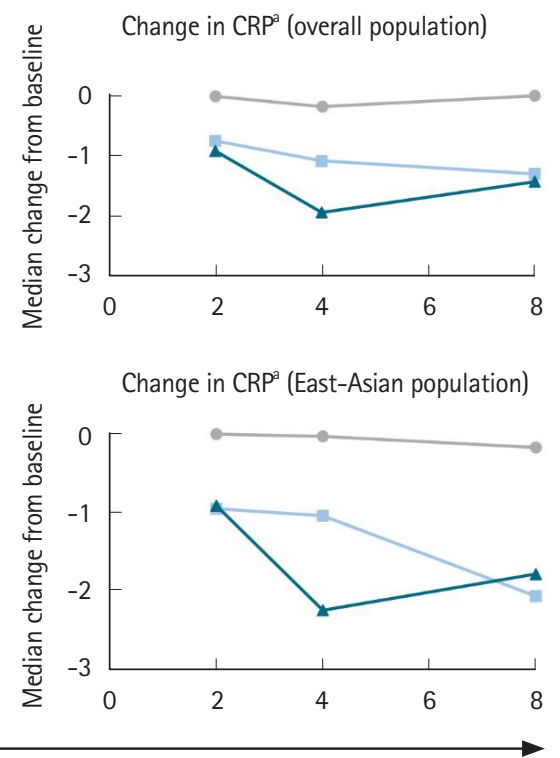

(1)

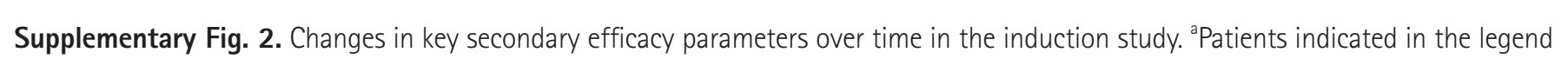
are those randomized at week 0 . UST, ustekinumab; F-CP, fecal calprotectin; CRP, C-reactive protein. 


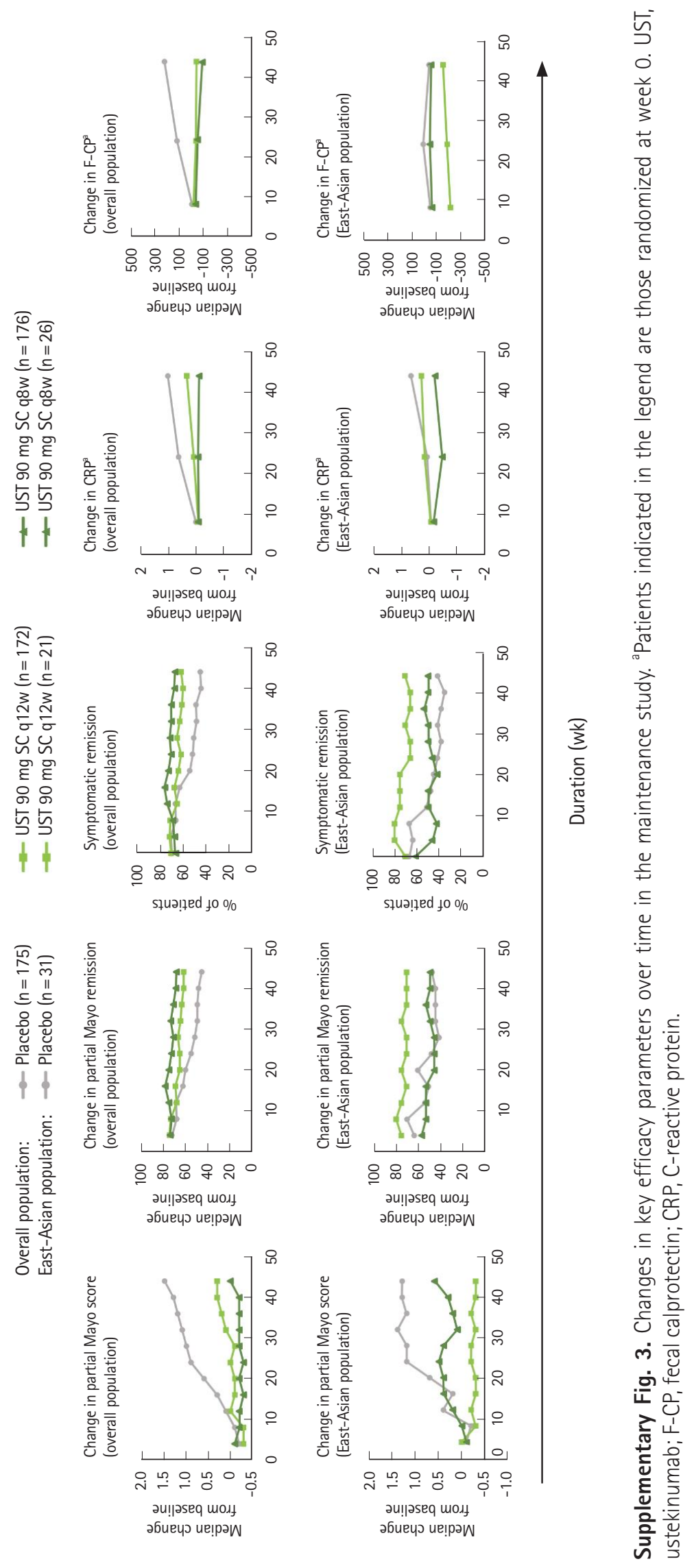

www.irjournal.org 


\section{A Induction study}

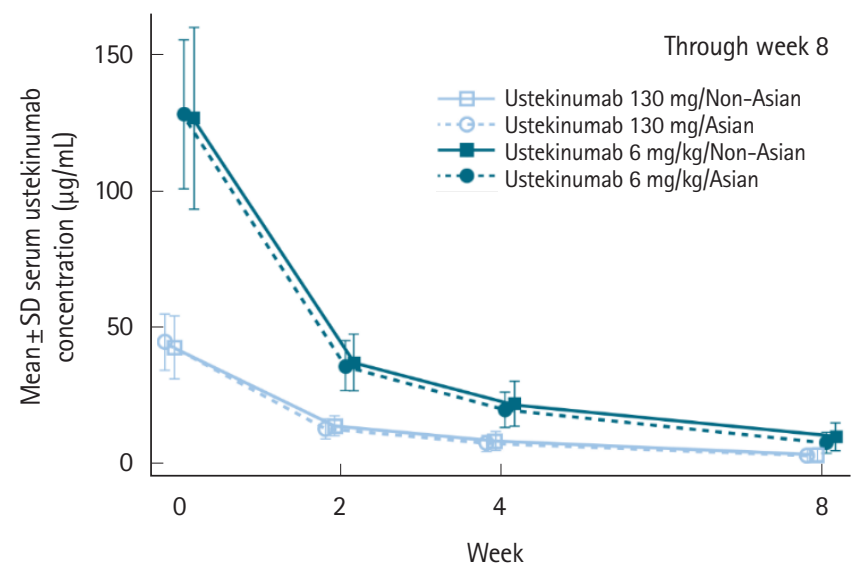

B Maintenance study
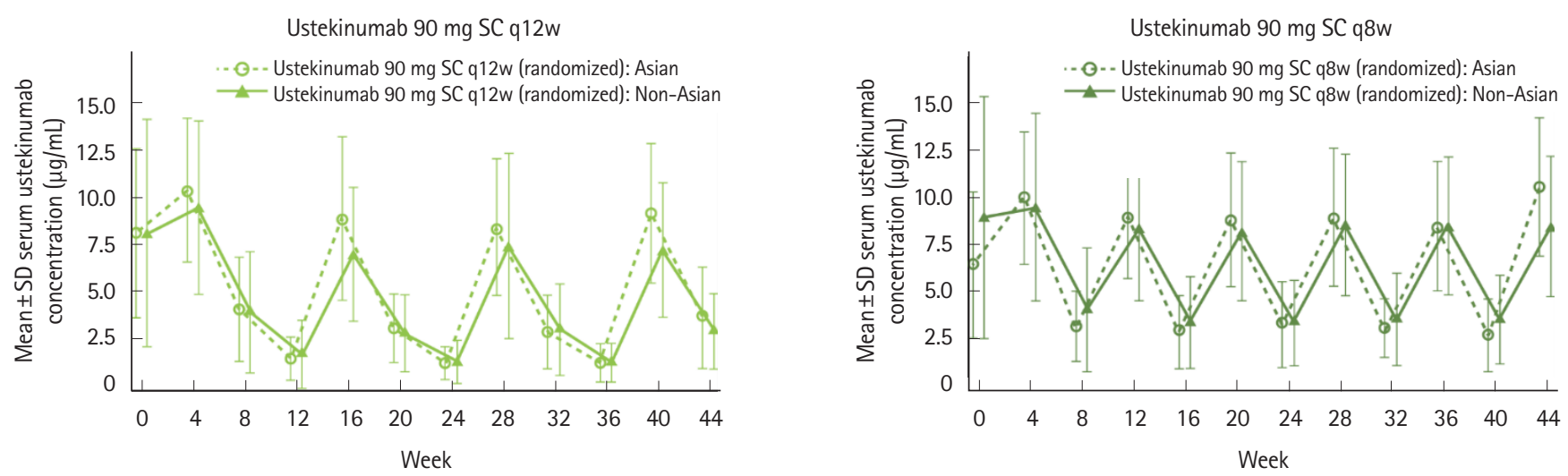

Supplementary Fig. 4. (A, B) Serum ustekinumab concentrations $(\mu \mathrm{g} / \mathrm{mL})$ in East-Asian versus non-Asian Population (PK analysis set). SC, subcutaneous; q12w, every 12 weeks; q8w, every 8 weeks; SD, standard devaiton. 